\title{
Thyroid Gland Teratoma
}

National Cancer Institute

\section{Source}

National Cancer Institute. Thyroid Gland Teratoma. NCI Thesaurus. Code C46124.

A teratoma that involves, is continuous with, or completely replaces the thyroid gland. It is derived from all three embryonic germ cell layers. According to the level of differentiation of the tissues which comprise the tumor, teratomas are classified as benign (grade 0 or 1), immature (grade 2), and malignant (grade 3). Grade 0 teratomas contain only mature elements; grade 1 teratomas have a limited deg ree of immaturity; grade 2 teratomas have a more extensive degree of immaturity; grade 3 teratomas are composed exclusively of immature tissues. The prognosis depends on patient age, tumor size, and grade. 